\title{
Determinants of object choice and object attachment: Compensatory consumption in compulsive buying-shopping disorder and hoarding disorder
}

\author{
MELISSA M. NORBERG ${ }^{1}$, JONATHAN DAVID ${ }^{1}$, CASSANDRA CRONE ${ }^{1}$, VANI KAKAR ${ }^{1}$, CATHY KWOK ${ }^{1}$, \\ JAKE OLIVIER $^{2}$ and JESSICA R. GRISHAM ${ }^{3}$ \\ ${ }^{1}$ Department of Psychology, Centre for Emotional Health, Macquarie University, Sydney, NSW, Australia \\ ${ }^{2}$ School of Mathematics and Statistics, UNSW Sydney, Kensington, NSW, Australia \\ ${ }^{3}$ School of Psychology, UNSW Sydney, Kensington, NSW, Australia
}

(Received: October 7, 2019; revised manuscript received: December 1, 2019; accepted: December 2, 2019)

\begin{abstract}
Background and aims: Individuals who meet criteria for compulsive buying-shopping disorder (i.e., acquiring problems only) or hoarding disorder (i.e., acquiring and discarding problems) may acquire possessions to compensate for unmet belonging needs, but may do so in different ways. Those with compulsive buying-shopping disorder may acquire objects that they believe will relieve the distress associated with unmet belonging needs (e.g., objects that distract or comfort), whereas those with hoarding disorder may acquire objects that they believe achieve belonging needs (e.g., objects that have interpersonal connotations). Accordingly, this study examined whether a belongingness threat would drive individuals who excessively acquire possessions to choose a human-like object (person-shaped tea holder) or a comfort item (box of chamomile tea). Methods: One hundred seventy-five participants (57 self-reported excessive acquiring only; 118 self-reported excessive acquiring and difficulty discarding) recalled a time when they either felt supported or unsupported by a significant other before choosing an object to take home with them. Participants rated how anthropomorphic and comforting the objects were as well as how attached they became to their chosen object. Results: Unsupported individuals were more likely to acquire the comfort item than supported individuals; however, individuals with both acquiring and discarding problems were more likely to acquire the human-like item than those with an acquiring problem only. Comfort and anthropomorphism ratings predicted object choice and attachment. Discussions and conclusion: The current findings extend the Compensatory Consumer Behavior Model to include what factors determine strategy choice and object attachment.
\end{abstract}

Keywords: anthropomorphism, belonging, interpersonal problems, belonging needs, hoarding disorder, compulsive shopping

\section{INTRODUCTION}

Compulsive buying is associated with serious financial consequences, emotion regulation difficulties, and social isolation (Achtziger, Hubert, Kenning, Raab, \& Reisch, 2015; DeSarbo \& Edwards, 1996; Williams, 2012). Approximately half of individuals with compulsive buying tendencies also self-report clinically significant hoarding symptoms (Frost, Steketee, \& Williams, 2002; Mueller et al., 2007). Hoarding disorder (HD) is characterized by such extreme discarding difficulties that individuals are unable to use their homes for much other than storage (American Psychiatric Association, 2013). Excessive acquiring, whether or not accompanied by discarding problems, may be the result of unmet belonging needs (Fromm, 1947).

DeSarbo and Edwards (1996) postulated that compulsive buying helps individuals escape anxiety brought on by stressors, such as poor family communication and social isolation. In support of this assumption, greater familial conflict and greater social anxiety are associated with more compulsive buying (Harnish, Bridges, Gump, \& Carson, 2018; Rindfleish, Burroughs, \& Denton, 1997; Roberts, Pullig, \& David, 2019; Singh \& Nayak, 2016). Moreover, compulsive buyers (CBs) report being lonely prior to a buying episode (Faber \& O'Guinn, 1992) and seek-out the interpersonal contact offered by retail outlets (Krueger, 1988).

Individuals with HD may also excessively acquire possessions to compensate for unmet belonging needs. Adults with hoarding problems report experiencing more interpersonal problems, difficulties in relationships, and less social support compared to community controls (Grisham, Steketee, \& Frost, 2008; Medard \& Kellett, 2014). Not only are adults with hoarding problems more likely to be unmarried and to live alone compared to the general population (Kim, Steketee, \& Frost, 2001), but

\footnotetext{
* Corresponding author: Melissa M. Norberg; Department of Psychology, Centre for Emotional Health, Macquarie University, Building 4 First Walk, Room 714, Sydney 2109, NSW, Australia; Phone: +61 29850 8127; E-mail: melissa.norberg@mq.edu.au
}

This is an open-access article distributed under the terms of the Creative Commons Attribution-NonCommercial 4.0 International License, which permits unrestricted use, distribution, and reproduction in any medium for non-commercial purposes, provided the original author and source are credited, a link to the CC License is provided, and changes - if any - are indicated. 
their family members are more rejecting and hostile toward them than family members are toward relatives with obsessive-compulsive disorder (Tolin, Frost, Steketee, \& Fitch, 2008). Notably, greater family rejection, greater interpersonal problems, and lower levels of social support are associated with greater hoarding severity (Medard \& Kellett, 2014; Norberg, Crone, Kakar, Kwok, \& Grisham, under review; Tolin et al., 2008).

The Compensatory Consumer Behavior Model posits that when individuals experience a discrepancy between their current self and their desired self (i.e., self-discrepancy), they can be motivated to resolve this self-discrepancy and the associated psychological discomfort by consuming goods (Mandel, Rucker, Levav, \& Galinsky, 2017). The model further specifies that self-discrepancies can be resolved through five different consumer strategies: direct resolution, symbolic-self completion, dissociation, escapism, and fluid compensation (Mandel et al., 2017). For example, individuals who experience a social belongingness self-discrepancy can compensate by (a) acquiring an object that directly resolves the discrepancy (e.g., buying a self-help book for friendship advice; direct resolution), (b) acquiring an object that signals affiliation (e.g., buying a Tamagotchi toy; symbolic-self completion), (c) behaving in a way that separates the individual from the discrepancy (e.g., getting a tattoo when a tattoo violates the social norms of the group; dissociation), (d) acquiring an object that provides comfort or distraction from the discrepancy (e.g., consuming comfort food; escapism), or (e) behaving in a way that reinforces an aspect of their identity separate from their self-discrepancy (e.g., buying clothing to feel more masculine or feminine; fluid compensation). Although this model specifies that consumer preferences change as a function of how people feel interpersonally, it does not tell us what leads an individual to choose one strategy over another.

Individuals who compulsively buy material goods may be especially attracted to objects perceived capable of relieving the distress associated with a self-discrepancy (i.e., escapism). CBs report being motivated to buy possessions to improve their mood and evidence strong improvements in their mood immediately after making purchases (Dittmar, 2005). In fact, prior research has shown that emotions are the strongest predictors of compulsive buying, such that negative emotions precede compulsive buying and emotional improvements follow compulsive buying (Dittmar, Long, \& Bond, 2007; Miltenberger et al., 2003; Müller et al., 2012; Sneath, Lacey, $\&$ Kennett-Hensel, 2009). However, CBs tend to regret their purchases, and thus improvements in mood tend to be short-lived (Dittmar, 2005; Müller et al., 2012). Such afterpurchase regret likely reduces object attachment and facilitates discarding practices, unlike individuals with HD who report greater attachment to their objects after acquiring them (Grisham et al., 2009).

Individuals with HD may be particularly prone to acquiring objects that signal social affiliation (i.e., symbolicself completion) due to high-trait tendencies to anthropomorphize objects. HD individuals report having a stronger anxious attachment style than individuals without a psychological disorder or who only have excessive acquiring tendencies (Grisham, Martyn, Kerin, Baldwin, \& Norberg, 2018; Norberg et al., under review) and a stronger anxious attachment style is associated with stronger tendencies to anthropomorphize inanimate objects (Kwok, Crone, Arden, \& Norberg, 2018). Greater tendencies to view possessions as human-like are associated with more excessive buying, greater acquisition of free items, greater discarding difficulties, and stronger object attachment (Burgess, Graves, \& Frost, 2018; Kwok, Grisham, \& Norberg, 2018; Norberg, Crone, Kwok, \& Grisham, 2018; Timpano \& Shaw, 2013). Thus, anthropomorphizing possessions may increase object attachment and lead to the eventual build-up of clutter that is characteristic of HD.

Based on the accumulating research, we hypothesized that when given a choice between a comfort item (chamomile tea) and a human-like object (person-shaped tea holder), an individual's acquiring status would interact with a priming manipulation. Specifically, we hypothesized that when individuals who only have an acquiring problem (CB) are primed to feel unsupported by a significant other that they would be more likely to choose a comfort item than those primed to feel supported, as we expected these individuals to engage in escapism (i.e., choosing an object to relieve the distress associated with a self-discrepancy). On the other hand, we expected that individuals with both acquiring and discarding problems (HD) would choose a human-like object regardless of priming condition, as we expected these individuals to engage in symbolic selfcompletion (i.e., choosing an object to give the illusion that a self-discrepancy has been resolved). Importantly, we did not expect the priming condition to influence object choice for the HD participants as we expected their chronic unmet belonging needs to override the supported prime. We also hypothesized that participants would become more strongly attached to the human-like object than the comfort item, given that anthropomorphism should increase object attachment. Accordingly, we expected that greater anthropomorphism would be related to greater object attachment. We also expected that individuals in the unsupported prime condition and in the HD group would report a greater belongingness threat, greater negative emotion, greater anthropomorphism, and stronger object attachment than their comparisons. Finally, we expected that greater comfort ratings would be related to object choice for the $\mathrm{CB}$ group, whereas greater anthropomorphism would be related to object choice for the HD group. Testing these predictions about individuals with two different types of maladaptive acquiring tendencies will hopefully shed light on how we might better treat these distinct conditions.

\section{METHODS}

\section{Participants}

Recruitment materials were distributed online and in public areas local to the university where the research was conducted. Undergraduate psychology students were also recruited from SONA, an online research participant database. To determine eligibility, interested individuals completed the Saving Inventory - Revised (SI-R; Frost, Steketee, \& Grisham, 2004). One hundred seventy-five individuals who scored higher than 11 on the Excessive 
Acquisition subscale of the SI-R were invited to participate as such scores indicate clinically relevant acquiring behavior (Kellman-McFarlane et al., 2019). Individuals who scored 12 or below on the SI-R Difficulty Discarding subscale were assigned to the "compulsive buying" group $(N=59)$, whereas those who scored 15 or higher on this subscale fell above the clinical cut-off for HD (Kellman-McFarlane et al., 2019) and were assigned to the "acquiring and discarding difficulties" group (HD; $N=121)$. Persons with Difficulty Discarding scores of 13 and 14 were not eligible for this study, as we wanted to ensure that our two groups were distinct (see Table 1 for demographic information on age, gender, and ethnicity).

\section{Materials}

Significant other's prime. Participants were given 5 min to recall and describe their experiences with a significant other during a time of need. Participants were randomly assigned to "supported" or "unsupported" conditions. In line with Keefer, Landau, Rothschild, and Sullivan (2012), participants in the unsupported condition were asked to recall an instance in which a significant other did not support them, whereas participants in the supported condition were asked to recall an instance in which they were effectively supported.

Manipulation check. Participants responded to eight statements about how they currently felt on a 9-point Likert-type scale from 1 (not at all) to 9 (very much so), with 5 indicating "moderately." Items for the belongingness threat subscale included: "I feel treated unfairly," "I feel valued" (reverse-scored), and "I feel non-existent." Items for the negative emotions subscale included: "I feel sad," "I feel happy" (reverse-scored), "I feel lonely," "I feel frustrated," and "I feel angry." These items were adapted from the Felt Security Scale (Luke, Sedikides, \& Carnelley, 2012) and from previous research on ostracism (Zadro, Williams, \& Richardson, 2004) and affective processing of social exclusion (Gutz, Roepke, \& Renneberg, 2016). Items were averaged to obtain mean scores for belongingness threat and negative emotion. In this study, internal consistency for the belongingness threat subscale was $\alpha=.74$, while the negative emotions subscale was $\alpha=.86$.

Mock store. Participants were asked to imagine that they had gone back in time, such that the situation they wrote about had just happened. They were then shown two objects meant to target symbolic self-completion and escapism in a random order. Because objects with human-like physical features are more likely to be anthropomorphized (Aggarwal \& McGill, 2007), one item was included for its human-like characteristics (person-shaped tea holder). The other item was a box of chamomile tea because warm drinks, such as tea, are comforting (Spence, 2017; Steptoe et al., 2007). Similar to past research (Birwistle \& Tsim, 2005), participants responded to a 7-point Likert scale from 1 (not at all) to 7 (very much) regarding the extent to which each object would "provide comfort and emotional security." They also completed a measure of anthropomorphism after being shown each item (see below).

Anthropomorphism. The degree that each object was anthropomorphized was measured using a 6-item questionnaire, which was composed of items from Graves Anthropomorphic Task Scale (Burgess et al., 2018) and the Anthropomorphic Mental State Rating Scale (Epley, Akalis, Waytz, \& Cacioppo, 2008). Participants indicated on a 7-point Likert scale from 1 (not at all) to 7 (very much) to what extent (a) the object has intentions, (b) the object should be treated like a human, (c) the object is thoughtful and sympathetic, (d) they would like to name the object, (e) how much they would mourn the object like mourning the loss of a human if the object was destroyed, and (f) how much they wanted to talk to the object. Items were averaged to give a mean score. In this study, the internal validity of the anthropomorphism measure was $\alpha=.85$ for chamomile tea and $\alpha=.88$ for the tea holder.

Object Attachment Questionnaire - Revised (OAQ-R). Six items from the Object Attachment Questionnaire (Grisham et al., 2009) were used to measure object attachment as the remainder of the scale assesses constructs other than attachment (e.g., anthropomorphism). These items

Table 1. Demographic and clinical characteristics by group

\begin{tabular}{|c|c|c|c|c|c|c|}
\hline \multirow[b]{2}{*}{ Measure } & \multirow{2}{*}{$\frac{\text { Supported }}{n=83(\%)}$} & \multirow{2}{*}{$\frac{\text { Unsupported }}{n=92(\%)}$} & \multirow[b]{2}{*}{$\chi^{2}(d f)$ or $t(d f)$} & \multirow{2}{*}{$\frac{\text { Acquiring only (CB) }}{n=57(\%)}$} & \multirow{2}{*}{$\begin{array}{c}\begin{array}{c}\text { Acquiring and } \\
\text { discarding (HD) }\end{array} \\
n=118(\%)\end{array}$} & \multirow[b]{2}{*}{$\chi^{2}(d f)$ or $t(d f)$} \\
\hline & & & & & & \\
\hline Female & $67(80.7)$ & $73(79.3)$ & $1.27(2)$ & $48(84.2)$ & $92(78.0)$ & $1.25(2)$ \\
\hline Current student & $77(92.8)$ & $89(96.7)$ & $6.09(3)$ & $55(96.5)$ & $111(94.1)$ & $1.74(3)$ \\
\hline Ethnicity & & & $1.46(3)$ & & & $1.00(3)$ \\
\hline Anglo Australian & $24(28.9)$ & $29(31.5)$ & & $18(31.6)$ & $35(29.7)$ & \\
\hline Asian & $34(41.0)$ & $38(41.3)$ & & $21(36.8)$ & $51(43.2)$ & \\
\hline European & $14(16.9)$ & $13(14.1)$ & & $9(15.8)$ & $18(15.3)$ & \\
\hline Other & $11(13.2)$ & $12(13.1)$ & & $9(15.8)$ & $14(11.8)$ & \\
\hline Age & $22.58(6.90)$ & $20.95(5.25)$ & $-1.74(153)$ & $20.35(3.94)$ & $22.38(6.86)$ & $2.48(168)^{*}$ \\
\hline SI-R Acquisition & $15.17(3.66)$ & $15.90(3.44)$ & $1.37(173)$ & $14.04(2.83)$ & $16.29(3.65)$ & $4.48(139)^{* *}$ \\
\hline SI-R Discarding & $15.90(5.17)$ & $15.39(4.30)$ & $0.11(160)$ & $9.67(1.94)$ & $18.21(2.71)$ & $23.85(148)^{* *}$ \\
\hline SI-R Clutter & $13.64(7.33)$ & $14.39(6.53)$ & $0.72(173)$ & $10.25(6.73)$ & $15.86(6.24)$ & $5.44(173)^{* *}$ \\
\hline SI-R Total & 44.27 (12.99) & $45.68(10.79)$ & $0.78(173)$ & $33.95(8.55)$ & $50.36(9.28)$ & $11.25(173)^{* *}$ \\
\hline
\end{tabular}

Note. SI-R: Saving Inventory - Revised; CB: compulsive buyer; HD: hoarding disorder.

${ }^{*} p<.05 .{ }^{* *} p<.01$. 
asked about attachment and how much an object is liked, how easy it would be to give away, how distressed one would feel if it was lost or misplaced, and how much the object feels like a part of the self. Participants indicated the degree to which they agreed or disagreed with each item on a 7-point Likert scale from 1 (not at all/strongly disagree) to 7 (very much/strongly agree). Items were averaged to obtain a mean score. In this study, the internal validity of the OAQ-R was $\alpha=.85$.

Saving Inventory - Revised (SI-R). The SI-R is a 23-item questionnaire that measures excessive acquisition, difficulty discarding, and clutter (Frost et al., 2004). Participants indicated the degree to which they experienced each item on a 5-point Likert scale from 0 (none/not at all/never) to 4 (almost all/complete/extreme/very often). The SI-R has previously demonstrated good test-retest reliability, convergent and divergent validity, and good to strong internal consistency for the total scale and all three subscales ( $\alpha \geq .87$; Frost et al., 2004). In this study, the excessive acquisition, difficulty discarding, clutter, and total scales had internal consistencies of $\alpha=.58, .81, .90$, and .88, respectively. We examined all participants' data (i.e., excluded individuals and those who declined participation) and computed an $\alpha=.82$ for the Excessive Acquisition subscale. Therefore, the poor internal consistency obtained for this sample was likely attributable to most Excessive Acquisition scores residing close to our eligibility cut-off score (i.e., restricted range of scores; Cortina, 1993).

Demographics. Participants were asked about their gender, age, ethnicity, and whether they were currently studying at university.

\section{Procedure}

Participants first completed the significant others' prime and the manipulation check questionnaire, and then the experimenter showed participants the two items from the mock store, asking them to complete the anthropomorphism measure and comfort rating for each object. Next, the experimenter asked participants to choose one item to take home. After choosing their item, participants completed the OAQ-R for that item. Participants were then debriefed and received either course credit $(n=86)$ or a $\$ 20$ reimbursement $(n=94)$ for their contribution to the study.

\section{Statistical analyses}

Prior to hypothesis testing, we conducted a series of preliminary analyses. First, we excluded any individuals randomly assigned to the supported prime who reported an extreme lack of belonging or extreme negative emotions (i.e., scores $\geq 8.5$ ) and any individual randomly assigned to the unsupported prime who reported extreme belongingness or an absence of negative emotion (i.e., scores $\leq 1.5$ ), as such scores indicate that the primes were completely ineffective. Next, we used paired $t$-tests to examine whether participants anthropomorphized the person-shaped tea holder more so than the box of chamomile tea and whether participants felt that the tea was more comforting than the tea holder as we wanted to ensure that our chosen objects were differentially human-like and comforting in nature.
Then, we conducted Pearson's $\chi^{2}$ tests and independent samples $t$-tests to assess whether the experimental prime conditions and the acquiring groups differed on demographic and clinical characteristics (Table 1). In cases of unequal variance as determined by Levene's test for equality of variance, degrees of freedom were adjusted for the $t$-statistic. As the HD group was statistically significantly older than the CB group, age was included as a covariate when examining the effect of hoarding status on object choice and attachment.

To test our hypothesis that hoarding status would interact with our manipulation primes to influence object choice, we conducted a $2 \times 2$ logistic regression controlling for age. Odds ratios (ORs) and $95 \%$ confidence intervals are reported as measures of effect size for logistic regression. According to Olivier, May, and Bell (2017), ORs for a nonrare positive outcome are 1.32 for small, 2.38 for medium, and 4.70 for large. For a negative non-rare outcome, the reciprocals of these values correspond to the relative effect sizes of $0.76,0.42$, and 0.21 .

To test our hypotheses that the unsupported prime condition and HD group would report greater belongingness threats, greater negative emotion, greater anthropomorphism, and stronger attachment to their chosen object than their comparisons, we conducted a series of analyses of covariance (ANCOVAs) that included age as a covariate and acquiring group and manipulation prime as fixed factors. Potential group differences in comfort ratings for the objects also were examined, but we did not expect any differences. Partial $\eta^{2}$ is reported as a measure of effect size for ANCOVA, with small, medium, and large effects represented by $0.01,0.06$, and 0.14 , respectively (Richardson, 2011).

We used an independent $t$-test and Cohen's $d(0.20,0.50$, and 0.80 indicate small, medium, and large effect sizes, respectively; Cohen, 1988) to test our hypothesis that, as a whole, participants would report stronger attachment to the tea holder than the chamomile tea.

To examine our hypotheses that greater comfort and anthropomorphism would be related to object choice and greater object attachment, we conducted a series of correlations for each condition and group. Examination of $\mathrm{Q}-\mathrm{Q}$ plots suggested that anthropomorphism of the chamomile tea was not normally distributed and thus Spearman's rank order correlations were conducted when examining this variable. Small, medium, and large correlation coefficients are represented by $0.1,0.3$, and 0.5 , respectively (Cohen, 1988). Next, we examined if these within-group correlations were statistically different from each other using Fisher's $Z$-tests. The critical value for a two-tailed $Z$ is 1.96 for $p<.05$. Finally, we conducted post-hoc Pearson's correlations to understand if greater object attachment was associated with more severe acquiring, discarding, and clutter problems.

\section{Ethics}

The study procedures were carried out in accordance with the Declaration of Helsinki. The human research ethics committee at Macquarie University approved the study. All participants provided voluntary informed consent prior to initiating the study. 


\section{RESULTS}

\section{Preliminary analyses}

After exclusions, 175 participants remained for analysis. As we were primarily interested in assessing the effect of the experimental manipulation on object choice, five participants were excluded from the unsupported prime condition due to failure to engage in the task, measured by the report of a belongingness threat and negative emotion following the manipulation ( $n=92$; results did not meaningfully change when including these five participants). No participant was excluded from the supported prime condition $(n=83)$. Of the 175 participants, 57 participants reported acquiring problems only (CB group) and 118 participants reported both acquiring and discarding difficulties (HD group). Forty-nine percent of the $\mathrm{CB}$ group was randomized to the supported condition ( $n=28)$, whereas $47 \%$ of the HD group was randomized to the unsupported condition $(n=56)$.

Paired samples $t$-tests revealed that participants anthropomorphized the person-shaped tea holder $(M=2.66$, $S D=1.36)$ more than the box of chamomile tea $(M=1.65$, $\left.S D=0.95 ; t_{(174)}=11.58, p<.001, d=0.88\right)$. On the other hand, participants rated the chamomile tea $(M=4.31$, $S D=1.62)$ as more comforting than the tea holder $\left(M=3.34, S D=1.73 ; t_{(174)}=6.38, p<.001, d=0.71\right)$.

Randomization was effective as participants from the supported/unsupported prime conditions were similar to demographic and clinical characteristics (Table 1). Participants from the HD group were older in age and reported more acquiring, discarding, and clutter problems than those from the CB group. The HD group obtained mean SI-R acquisition and discarding subscale scores comparable to clinical HD samples, but obtained slightly lower mean clutter subscale and total scores. However, these latter scores were within one standard deviation $(S D)$ of the clinical means (Kellman-McFarlane et al., 2019). The CB group obtained mean SI-R acquiring, discarding, and total scores comparable to clinical CB samples; however, it obtained a mean clutter score 1.23 SD higher than a prior clinical CB sample (Mueller et al., 2007). Despite being higher than average for a CB sample, this clutter score was similar to average non-clinical samples (Frost et al., 2004).

\section{Effect of the primes and hoarding status on object choice}

Overall, 59 individuals chose the chamomile tea and 116 individuals chose the person-shaped tea holder. The results of the logistic regression analysis, controlling for age, indicated that the hypothesized interaction between manipulation prime and acquiring status was not statistically significant $(b=1.17, S E=0.71, p=.10)$. As such, we removed the interaction from the model and reran the analysis for main effects only. The final logistic regression model suggested that individuals who were primed to feel unsupported were more likely to choose the chamomile tea when compared to individuals who were primed to feel supported $(b=0.93, S E=0.35, p=.007, \mathrm{OR}=2.54,95 \%$ $\mathrm{CI}=1.29,4.99)$ and that the HD group was less likely to choose the chamomile tea when compared to the $\mathrm{CB}$ group

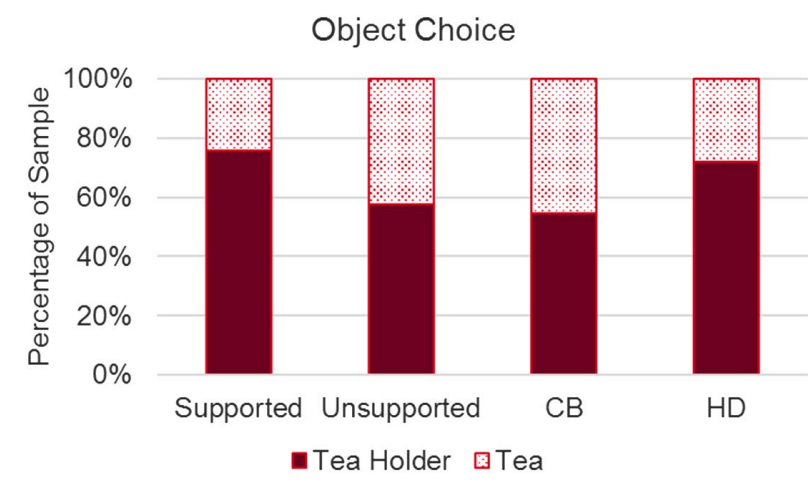

Figure 1. Object choice by significant other's prime and acquiring status

$(b=-0.88, S E=0.35, p=.01, \mathrm{OR}=0.42,95 \% \mathrm{CI}=0.21$, $0.83)$. Figure 1 demonstrates object choice by significant other's prime and acquiring status.

\section{Condition and group differences in belongingness threat and negative emotion}

Table 2 displays the adjusted means for belongingness threat and negative emotion for each condition and group. The results from the ANCOVA methods indicated that, as hypothesized, participants in the unsupported prime condition reported a greater belongingness threat $[F(1,171)=$ 86.23, $\left.p<.001, \eta_{p}{ }^{2}=.34\right]$ and greater negative emotion $\left[F(1,171)=91.51, p<.001, \eta_{p}{ }^{2}=.35\right]$ than participants in the supported prime condition. Unexpectedly, the HD group did not report a greater belongingness threat $[F(1,171)=$ $\left.1.11, p=.29, \eta_{p}^{2}=.006\right]$ nor greater negative emotions $\left[F(1,171)=2.45, p=.12, \eta_{p}{ }^{2}=.01\right]$ than the CB group.

\section{Condition and group differences in comfort, anthropomorphism, and object attachment}

Table 2 displays the adjusted means for comfort, anthropomorphism, and object attachment for each condition and group. Unexpectedly, ANCOVA methods revealed that the supported and unsupported conditions did not statistically differ on anthropomorphism of the tea holder $[F(1,171)=$ $\left.0.31, p=.58, \eta_{p}^{2}=.002\right]$, anthropomorphism of the chamomile tea $\left[F(1,171)=0.004, p=.95, \eta_{p}{ }^{2}=.000\right]$, or on object attachment $\left[F(1,171)=1.18, p=.28, \eta_{p}{ }^{2}=.007\right]$. They also did not differ on how comforting they believed the tea holder $\left[F(1,171)=0.003, p=.95, \eta_{p}{ }^{2}=.000\right]$ and chamomile tea to be $\left[F(1,171)=0.58, p=.45, \eta_{p}{ }^{2}=.003\right]$.

Contrary to prediction, the HD group did not report greater anthropomorphism of the chamomile tea $[F(1,171)=1.88$, $\left.p=.17, \eta_{p}{ }^{2}=.01\right]$ compared to the CB group; however, they did report stronger anthropomorphism of the tea holder $\left[F(1,171)=9.31, p=.003, \eta_{p}^{2}=.05\right]$ and greater object attachment $\left[F(1,171)=8.68, p=.004, \eta_{p}{ }^{2}=.05\right]$ than did the $\mathrm{CB}$ group. In terms of comfort, the $\mathrm{HD}$ and $\mathrm{CB}$ groups reported similar ratings for the tea holder $[F(1,171)=2.23$, $\left.p=.13, \eta_{p}{ }^{2}=.01\right]$. Comfort ratings were also similar for chamomile tea $\left[F(1,171)=0.11, p=.74, \eta_{p}^{2}=.01\right]$.

When examining the sample as a whole, participants reported being slightly more attached to the tea holder 
Table 2. One-way analysis of covariance - Adjusted means

\begin{tabular}{|c|c|c|c|c|}
\hline & Supported $(n=83)$ & Unsupported $(n=92)$ & $\begin{array}{l}\text { Acquiring only } \\
(\mathrm{CB} ; n=57)\end{array}$ & $\begin{array}{l}\text { Acquiring and discarding } \\
(\mathrm{HD} ; n=118)\end{array}$ \\
\hline Measure & $M(S E)$ & $M(S E)$ & $M(S E)$ & $M(S E)$ \\
\hline Belongingness Threat & $2.53(0.17)^{* *}$ & $4.67(0.17)^{* *}$ & $3.47(0.20)$ & $3.73(0.14)$ \\
\hline Negative Emotions & $2.88(0.17)^{* *}$ & $5.09(0.17)^{* *}$ & $3.79(0.20)$ & $4.18(0.14)$ \\
\hline \multicolumn{5}{|l|}{ Comfort } \\
\hline Tea holder & $3.27(0.20)$ & $3.25(0.19)$ & $3.05(0.23)$ & $3.45(0.16)$ \\
\hline Chamomile tea & $4.20(0.18)$ & $4.39(0.18)$ & $4.25(0.22)$ & $4.34(0.15)$ \\
\hline \multicolumn{5}{|l|}{ Anthropomorphism } \\
\hline Tea holder & $2.60(0.15)$ & $2.49(0.15)$ & $2.21(0.18)^{* *}$ & $2.88(0.12)^{* *}$ \\
\hline Chamomile tea & $1.61(0.11)$ & $1.62(0.10)$ & $1.51(0.13)$ & $1.72(0.09)$ \\
\hline OAQ-R & $3.52(0.13)$ & $3.71(0.13)$ & $3.34(0.15)^{* *}$ & $3.89(0.10)^{* *}$ \\
\hline
\end{tabular}

Note. Groups were compared by manipulation prime (supported/unsupported) and by acquiring and discarding status (CB/HD). OAQ-R: Object Attachment Questionnaire - Revised; CB: compulsive buyer; HD: hoarding disorder.

$* * p<.01$.

$(M=3.83, S D=1.14)$ than the chamomile tea $[M=3.48$, $S D=1.21 ; t(173)=1.93, p=.06, d=0.30]$, although this magnitude of difference was not statistically significant.

\section{Associations between anthropomorphism, comfort, and object choice}

Table 3 presents zero-order correlations for linear relationships between anthropomorphism, comfort, and object choice. In general, anthropomorphism and comfort ratings were not related to object choice. However, greater anthropomorphism of the tea holder after the unsupported prime was associated with taking the tea holder home, whereas greater anthropomorphism of the chamomile tea after experiencing the supported prime was associated with taking the box of tea home. Finding the tea holder more comforting after the unsupported prime was associated with taking the tea holder home, whereas believing the chamomile tea to be more comforting was associated with taking the chamomile tea home for the HD group.
The relationship between the level comfort provided by the tea holder and choosing the tea holder was statistically different for the supported and unsupported priming groups $(Z=2.02, p<.05)$, as was the relationship between the human-like nature of the tea holder and choosing the tea holder $(Z=2.77, p<.05)$. No other correlations significantly differed between the experimental primes and acquiring groups.

\section{Associations between anthropomorphism, comfort, and object attachment}

In support of our hypothesis, anthropomorphism of the chosen object demonstrated large positive relationships with degree of attachment to that object for every group and condition (Table 3 ). On the other hand, comfort consistently demonstrated moderate positive relationships with object attachment, except for the CB group.

The relationship between anthropomorphism of the chosen object and object attachment was statistically stronger

Table 3. Zero-order correlations

\begin{tabular}{|c|c|c|c|c|c|c|c|c|}
\hline \multirow[b]{2}{*}{ Measure } & \multicolumn{2}{|c|}{ Supported $(n=83)$} & \multicolumn{2}{|c|}{ Unsupported $(n=92)$} & \multicolumn{2}{|c|}{$\begin{array}{l}\text { Acquiring only } \\
(\mathrm{CB} ; n=57)\end{array}$} & \multicolumn{2}{|c|}{$\begin{array}{l}\text { Acquiring and discarding } \\
(\mathrm{HD} ; n=118)\end{array}$} \\
\hline & Choice & Attachment & Choice & Attachment & Choice & Attachment & Choice & Attachment \\
\hline \multicolumn{9}{|l|}{ Comfort } \\
\hline Tea holder & -.01 & - & $-.31 * *$ & - & -.11 & - & -.18 & - \\
\hline Chamomile tea & .21 & - & .20 & - & .19 & - & $.23 *$ & - \\
\hline Chosen item & - & $.42 * *$ & - & $.28 * *$ & - & .23 & - & $.42 * *$ \\
\hline \multicolumn{9}{|l|}{ Anthropomorphism } \\
\hline Tea holder & .17 & - & $-.25^{*}$ & - & .03 & - & -.15 & - \\
\hline Chamomile tea & $.27 *$ & - & .03 & - & .16 & - & .18 & - \\
\hline Chosen item & - & $.71 * *$ & - & $.50 * *$ & - & $.67 * *$ & - & $.55^{* *}$ \\
\hline
\end{tabular}

Note. Object choice: $0=$ tea holder, $1=$ chamomile tea. Participants provided comfort and anthropomorphism ratings for both objects before choosing an item, whereas participants provided attachment ratings only for their object of choice after selecting it. Pearson's correlations are reported for associations that did not include anthropomorphism of the chamomile tea, for which Spearman's rank order correlations were used. CB: compulsive buyer; HD: hoarding disorder.

${ }^{*} p<.05 . * * p<.01$ 
for individuals who received the supported prime than that those that received the unsupported prime $(Z=2.19$, $p<.05)$. No other correlations significantly differed between the experimental primes and acquiring groups.

\section{Object attachment and acquiring and saving severity}

Greater object attachment was associated with more severe acquiring problems $(r=.29, p<.01)$, discarding problems $(r=.28, p<.01)$, clutter $(r=.26, p<.01)$, and hoarding problems in general $(r=.35, p<.01)$.

\section{DISCUSSION}

The aim of this study was to examine whether a belongingness threat would differentially influence object choice and object ratings for individuals who only exhibited compulsive acquiring problems as compared to those who also exhibited discarding problems. Our hypothesis regarding an interaction between acquiring status and condition was not supported. However, we found support for main effects. After participants experienced the unsupported prime, the odds of choosing chamomile tea were $154 \%$ greater compared to participants who experienced the supported prime. Individuals in the unsupported prime were likely to deviate from this trend when they perceived the tea holder to be highly human-like and comforting. We also found that the HD group anthropomorphized the tea holder more so than did the CB group and that the odds the HD group chose the tea holder was $138 \%$ greater than the $\mathrm{CB}$ group. HD individuals were likely to choose the chamomile tea if they perceived it to be highly comforting. Taken together, these results show that a belongingness threat and the presence of discarding problems influence a person's object choices, and in some cases, this may be the result of how much individuals believe an object resembles a human and/or how much they believe it can comfort them.

We also demonstrated that object attachment (rated after choosing the object) was influenced by the comforting and human-like nature of an object (rated before choosing the object). Regardless of priming condition or acquiring status, anthropomorphism demonstrated large, positive correlations with object attachment. On the other hand, comfort consistently demonstrated moderate, positive correlations with object attachment, except for those who self-reported an acquiring problem only. For the CB group, comfort was not statistically significantly related to object attachment. Thus, a combination of anthropomorphism and comfort may be what makes it difficult for HD individuals to part with their possessions.

Some of these findings contradicted past research. First, unsupported participants were not more likely to choose the tea holder. In an earlier study, Mead, Baumeister, Stillman, Rawn, and Vohs (2011) found that 53\% of rejected participants purchased a social affiliation object as opposed to $13 \%$ of non-rejected participants. The social affiliation object was a spirit wristband from the university in which the study was being conducted. Pilot testing indicated that individuals would buy the wristband to communicate information about the self to others. In this study, the tea holder may have been wanted to communicate social information to the self, rather than to others. In addition, our findings may have differed because we sampled participants with an acquiring problem, whereas Mead et al. examined a nonselective sample. Second, we did not find that inducing a social belongingness threat increased object attachment. Past studies have assessed attachment to personal possessions as a whole rather than to specific objects newly acquired (Keefer et al., 2012). Thus, our findings may have differed because we assessed attachment to discrete objects and/or because we examined newly formed attachments rather than long-standing attachments. These replication failures highlight the need for researchers to carefully choose which objects they include in future studies and to comprehensively assess the function these objects serve for participants.

Our unsupported prime did not induce anthropomorphism; yet, past studies have found that acute and chronic loneliness are associated with anthropomorphism (Epley, Akalis, et al., 2008; Epley, Waytz, Akalis, \& Cacioppo, 2008). Specifically, feeling lonely frequently (i.e., "How often do you feel left out") has been related to greater anthropomorphism of technological gadgets with humanlike qualities, whereas a greater degree of loneliness (i.e., UCLA Loneliness Scale) and watching a social isolation scene from the movie Cast Away have been associated with describing pets as capable of providing social connection. As pets are very likely to be anthropomorphized because they are living beings with cognitive abilities with whom people can share their lives (Airenti, 2018), belongingness threats may more easily influence pet anthropomorphism than object anthropomorphism. Moreover, if frequent belongingness threats induce anthropomorphism, then a one-off experimental manipulation may not be enough to induce object anthropomorphism. This possibility seems likely given that individuals with acquiring and discarding difficulties, who have been found to have more interpersonal difficulties than individuals with acquiring problems only (Norberg et al., under review), anthropomorphized the person-shaped tea holder to a greater degree.

Finally, this study did not find that the comforting nature of the chamomile tea was related to choosing the tea for individuals with only an acquiring problem. As the strategy of escapism involves acquiring an object that provides comfort or distraction from a self-discrepancy, future research should examine if the distracting nature of an object, more so than its comforting properties, functions to increase acquisition for individuals who only have compulsive acquisition problems.

The Compensatory Consumer Behavior Model postulates that a belongingness threat may motivate individuals to use possessions in five different ways to deal with a selfdiscrepancy (Mandel et al., 2017). Relevant to this study are the strategies of symbolic self-completion and escapism. A chronic belongingness self-discrepancy (Norberg et al., under review) and a high tendency to anthropomorphize inanimate objects (Burgess et al., 2018; Neave, Tyson, McInnes, \& Hamilton, 2016; Timpano \& Shaw, 2013) may encourage individuals with HD to generally seek-out items that may provide a false sense that their belongingness needs have been met. However, when experiencing an acute 
belongingness threat, these individuals and individuals with compulsive shopping-buying disorder may be drawn to seeking out items that provide comfort. As anthropomorphism was a stronger predictor of object attachment than comfort, engaging in symbolic self-completion may be more harmful than engaging in escapism. In support of this assumption, past research has found that greater object attachment is related to more extensive acquiring, discarding, and clutter problems (Grisham et al., 2009; Kwok, Grisham, et al., 2018; Neave et al., 2016; Nedelisky \& Steele, 2009; Norberg, Keyan, \& Grisham, 2015).

The conclusions drawn from this study should be interpreted in light of its limitations. First, this study used a categorical approach to studying compulsive buying and HD. Although we used clinically valid cut-offs (KellmanMcFarlane et al., 2019) for categorizing individuals as opposed to artificial categorization (e.g., median split), dichotomizing continuous data reduces power and conceals possible non-linear relationships (Altman \& Royston, 2006). Thus, future studies may need to examine data continuously, especially if compulsive buying is found to only be a less severe form of HD rather than a qualitatively distinct disorder. Second, this study only examined behavior toward a knickknack and a food item when individuals with HD frequently save clothes, books, and letters as well (Mogan, Kyrios, Schweitzer, Yap, \& Moulding, 2012). Moreover, only two types of compensatory compensation were assessed. Allowing participants to choose between multiple objects that map onto Mandel et al.'s (2017) five strategies and including a non-acquiring option would provide more ecological validity. Asking people why they chose a particular object also would contribute to a greater understanding of why individuals use different strategies to compensate for an unmet need as some individuals may choose an object for an unexpected reason. For example, some individuals may choose a human-like object not for its anthropomorphic qualities, but for its aesthetic qualities. However, researchers need to remember that self-reported cognitive goals and "wanting" may not correspond as the latter is controlled by non-conscious associative processes (Berridge \& Robinson, 2016).

Third, this study was confined to studying attachment immediately after acquiring a consumer good. Typically, the field of consumer psychology examines decision making up until the point of a purchase, whereas the study of HD within clinical psychology focuses on decision-making about longheld possessions. A combined examination may provide a more complete understanding of object choice and object attachment. Fourth, as the study did not include a diagnostic interview, it is difficult to ascertain how many participants met diagnostic criteria for compulsive buying-shopping disorder or HD. Thus, future studies should incorporate diagnostic interviews. Fifth, even though the participants belonged to a multi-ethnic sample, the majority of the sample constituted young females. Although being young and female has been associated with an increased tendency for compulsive buying behavior (Maraz, Griffiths, \& Demetrovics, 2016), HD is just as prevalent for males and females (Postlethwaite, Kellett, \& Mataix-Cols, 2019) and is often considered a problem of old age because individuals tend to not seek treatment for it until their mid-to-late 50s (Frost, Ruby, \& Shuer, 2012; Gilliam et al., 2011; Muroff,
Steketee, Bratiotis, \& Ross, 2012). However, hoarding has an average age of onset of 16.7 years (Zaboski II et al., 2019). Thus, examining young people is both a strength and weakness. Studying young people allows us to develop ideas for the prevention of entrenched problems, but it also inhibits us from learning about hoarding in its most severe form. Future studies should aim to include both younger and older people, although this may be a problem for compulsive buying, which may not frequently occur in old age. It would be interesting to know if compulsive buying evolves into HD, at least for a segment of the population. Thus, longitudinal studies are greatly needed.

\section{CONCLUSIONS}

In conclusion, this study extended upon Mandel et al.'s (2017) Compensatory Consumer Behavior Model by investigating the factors that motivate an individual to acquire and become attached to objects. We found that unsupported individuals were more likely to acquire a comfort item than supported individuals. We also found that individuals with both acquiring and discarding difficulties were prone to choosing a human-like possession. Whereas prior research has shown that consumer preferences change as a function of how a person feels interpersonally, this study established that an object's perceived comforting and human-like nature affect choice as well as object attachment.

Funding sources: This work was supported by the International OCD Foundation (IOCDF). The IOCDF did not have any involvement in study design, or in the collection, analysis, interpretation of data, or in the writing of the report and in the decision to submit the article for publication.

Authors' contribution: $\mathrm{MMN}, \mathrm{CK}$, and JRG are responsible for the study concept and design. JD and MMN wrote "Introduction" section. CC wrote "Methods" section. CC, $\mathrm{JO}$, and MMN conducted statistical analyses and wrote "Results" section. VK, JD, and MMN wrote "Discussion" section. All authors edited drafts and approved the final version of the manuscript for submission.

Conflict of interest: The authors declare no conflict of interest.

Acknowledgements: The authors would like to thank Adam McMahon, Madeleine Keaveny, Irit Levy, and Tiffany Chan for their efforts in data collection.

\section{REFERENCES}

Achtziger, A., Hubert, M., Kenning, P., Raab, G., \& Reisch, L. (2015). Debt out of control: The links between self-control, compulsive buying, and real debts. Journal of Economic Psychology, 49, 141-149. doi:10.1016/j.joep.2015.04.003 
Aggarwal, P., \& McGill, A. L. (2007). Is that car smiling at me? Schema congruity as a basis for evaluating anthropomorphized products. Journal of Consumer Research, 34(4), 468-479. doi: $10.1086 / 518544$

Airenti, G. (2018). The development of anthropomorphism in interaction: Intersubjectivity, imagination, and theory of mind. Frontiers in Psychology, 9, 2136. doi:10.3389/fpsyg.2018.02136

Altman, D. G., \& Royston, P. (2006). The cost of dichotomising continuous variables. British Medical Journal, 332(7549), 1080. doi:10.1136/bmj.332.7549.1080

American Psychiatric Association. (2013). Diagnostic and statistical manual of mental disorders (5th ed.). Washington, DC: American Psychiatric Publishing.

Berridge, K. C., \& Robinson, T. E. (2016). Liking, wanting and the incentive-sensitization theory of addiction. American Psychologist, 71(8), 670-679. doi:10.1037/amp0000059

Birwistle, G., \& Tsim, C. (2005). Consumer purchasing behaviour: An investigation of the UK mature women's clothing market. Journal of Consumer Behaviour, 4(6), 453-464. doi:10.1002/ cb. 31

Burgess, A. M., Graves, L. M., \& Frost, R. O. (2018). My possessions need me: Anthropomorphism and hoarding. Scandinavian Journal of Psychology, 59(3), 340-348. doi:10.1111/ sjop. 12441

Cohen, J. (1988). Statistical power analysis for the behavioral sciences (2nd ed.). Hillsdale, NJ: Lawrence Erlbaum Associates.

Cortina, J. M. (1993). What is coefficient alpha? An examination of theory and applications. Journal of Applied Psychology, 78(1), 98-104. doi:10.1037/0021-9010.78.1.98

DeSarbo, W. S., \& Edwards, E. A. (1996). Typologies of compulsive buying behavior: A constrained clusterwise regression approach. Journal of Consumer Psychology, 5(3), 231-262. doi:10.1207/s15327663jcp0503_02

Dittmar, H. (2005). A new look at "compulsive buying": Self-discrepancies and materialistic values as predictors of compulsive buying tendency. Journal of Social and Clinical Psychology, 24(6), 832-859. doi:10.1521/jscp.2005.24.6.832

Dittmar, H., Long, K., \& Bond, R. (2007). When a better self is only a click away: Associations between materialistic values, emotional and identity-related buying motives, and compulsive buying tendency online. Journal of Social and Clinical Psychology, 26(3), 334-361. doi:10.1521/jscp.2007.26.3.334

Epley, N., Akalis, S., Waytz, A., \& Cacioppo, J. T. (2008). Creating social connection through inferential reproduction. Psychological Science, 19(2), 114-120. doi:10.1111/j.14679280.2008.02056.x

Epley, N., Waytz, A., Akalis, S., \& Cacioppo, J. T. (2008). When we need a human: Motivational determinants of anthropomorphism. Social Cognition, 26(2), 143-155. doi:10.1521/soco. 2008.26.2.143

Faber, R. J., \& O'Guinn, T. C. (1992). A clinical screener for compulsive buying. Journal of Consumer Research, 19(3), 459-469. doi:10.1086/209315

Fromm, E. (1947). Man for himself: An inquiry into the psychology of ethics. New York, NY: Rinehart.

Frost, R. O., Ruby, D., \& Shuer, L. J. (2012). The buried in treasures workshop: Waitlist control trial of facilitated support groups for hoarding. Behaviour Research and Therapy, 50(11), 661-667. doi:10.1016/j.brat.2012.08.004

Frost, R. O., Steketee, G., \& Grisham, J. R. (2004). Measurement of compulsive hoarding: Saving Inventory-Revised. Behaviour
Research and Therapy, 42(10), 1163-1182. doi:10.1016/ j.brat.2003.07.006

Frost, R. O., Steketee, G., \& Williams, L. (2002). Compulsive buying, compulsive hoarding, and obsessive-compulsive disorder. Behavior Therapy, 33(2), 201-214. doi:10.1016/S00057894(02)80025-9

Gilliam, C. M., Norberg, M. M., Villavicencio, A., Morrison, S., Hannan, S. E., \& Tolin, D. F. (2011). Group cognitivebehavioral therapy for hoarding disorder: An open trial. Behaviour Research and Therapy, 49(11), 802-807. doi:10.1016/ j.brat.2011.08.008

Grisham, J. R., Frost, R. O., Steketee, G., Tarkoff, A., Kim, H.-J., \& Hood, S. (2009). Formation of attachments to possessions in compulsive hoarding. Journal of Anxiety Disorders, 23(3), 357-361. doi:10.1016/j.janxdis.2008.12.006

Grisham, J. R., Martyn, C., Kerin, F., Baldwin, P. A., \& Norberg, M. M. (2018). Interpersonal functioning in hoarding disorder: An examination of attachment styles and emotion regulation in response to interpersonal stress. Journal of Obsessive-Compulsive and Related Disorders, 16, 43-49. doi:10.1016/j.jocrd.2017. 12.001

Grisham, J. R., Steketee, G., \& Frost, R. O. (2008). Interpersonal problems and emotional intelligence in compulsive hoarding. Depression and Anxiety, 25(9), E63-E71. doi:10.1002/da.20327

Gutz, L., Roepke, S., \& Renneberg, B. (2016). Cognitive and affective processing of social exclusion in borderline personality disorder and social anxiety disorder. Behaviour Research and Therapy, 87, 70-75. doi:10.1016/j.brat.2016.08.020

Harnish, R. J., Bridges, K. R., Gump, J. T., \& Carson, A. E. (2018). The maladaptive pursuit of consumption: The impact of materialism, pain of paying, social anxiety, social support, and loneliness on compulsive buying. International Journal of Mental Health and Addiction, 17(6), 1401-1416. doi:10.1007/ s11469-018-9883-y

Keefer, L. A., Landau, M. J., Rothschild, Z. K., \& Sullivan, D. (2012). Attachment to objects as compensation for close others' perceived unreliability. Journal of Experimental Social Psychology, 48(4), 912-917. doi:10.1016/j.jesp.2012.02.007

Kellman-McFarlane, K., Stewart, B., Woody, S., Ayers, C. R., Dozier, M. E., Frost, R. O., Grisham, J., Isemann, S., Steketee, G., Tolin, D. F., \& Welstead, A. (2019). Saving inventory Revised: Psychometric performance across the lifespan. Journal of Affective Disorders, 252, 358-364. doi:10.1016/j.jad. 2019.04.007

Kim, H.-J., Steketee, G., \& Frost, R. O. (2001). Hoarding by elderly people. Health and Social Work, 26(3), 176-184. doi:10.1093/hsw/26.3.176

Krueger, D. W. (1988). On compulsive shopping and spending: A psychodynamic inquiry. American Journal of Psychotherapy, 42(4), 574-584. doi:10.1176/appi.psychotherapy.1988.42.4.574

Kwok, C., Crone, C., Arden, Y., \& Norberg, M. M. (2018). Seeing human when feeling insecure and wanting closeness: A systematic review into insecure attachment styles and anthropomorphism. Personality and Individual Differences, 127, 1-9. doi:10.1016/j.paid.2018.01.037

Kwok, C., Grisham, J., \& Norberg, M. M. (2018). Object attachment: Humanness increases sentimental and instrumental value. Journal of Behavioral Addictions, 7(2), 1-11. doi:10.1556/ 2006.7.2018.98

Luke, M. A., Sedikides, C., \& Carnelley, K. (2012). Your love lifts me higher! The energizing quality of secure relationships. 
Personality and Social Psychology Bulletin, 38(6), 721-733. doi: $10.1177 / 0146167211436117$

Mandel, N., Rucker, D. D., Levav, J., \& Galinsky, A. D. (2017). The compensatory consumer behavior model: How selfdiscrepancies drive consumer behavior. Journal of Consumer Psychology, 27(1), 133-146. doi:10.1016/j.jcps.2016.05.003

Maraz, A., Griffiths, M. D., \& Demetrovics, Z. (2016). The prevalence of compulsive buying: A meta-analysis. Addiction, 111(3), 408-419. doi:10.1111/add.13223

Mead, N. L., Baumeister, R. F., Stillman, T. F., Rawn, C. D., \& Vohs, K. D. (2011). Social exclusion causes people to spend and consume strategically in the service of social affiliation. Journal of Consumer Research, 37(5), 902-919. doi:10.1086/656667

Medard, E., \& Kellett, S. (2014). The role of adult attachment and social support in hoarding disorder. Behavioural and Cognitive Psychotherapy, 42(5), 629-633. doi:10.1017/ S1352465813000659

Miltenberger, R. G., Redlin, J., Crosby, R., Stickney, M., Mitchell, J., Wonderlich, S., Faber, R., \& Smyth, J. (2003). Direct and retrospective assessment of factors contributing to compulsive buying. Journal of Behavior Therapy and Experimental Psychiatry, 34(1), 1-9. doi:10.1016/ S0005-7916(03)00002-8

Mogan, C., Kyrios, M., Schweitzer, I., Yap, K., \& Moulding, R. (2012). Phenomenology of hoarding - What is hoarded by individuals with hoarding disorder? Journal of ObsessiveCompulsive and Related Disorders, 1(4), 306-311. doi:10.1016/j.jocrd.2012.08.002

Mueller, A., Mueller, U., Albert, P., Mertens, C., Silbermann, A., Mitchell, J. E., \& de Zwaan, M. (2007). Hoarding in a compulsive buying sample. Behaviour Research and Therapy, 45(11), 2754-2763. doi:10.1016/j.brat.2007.07.012

Müller, A., Mitchell, J. E., Crosby, R. D., Cao, L., Johnson, J., Claes, L., \& de Zwaan, M. (2012). Mood states preceding and following compulsive buying episodes: An ecological momentary assessment study. Psychiatry Research, 200(2-3), 575-580. doi:10.1016/j.psychres.2012.04.015

Muroff, J., Steketee, G., Bratiotis, C., \& Ross, A. (2012). Group cognitive and behavioral therapy and bibliotherapy for hoarding: A pilot trial. Depression and Anxiety, 29(7), 597-604. doi:10.1002/da.21923

Neave, N., Tyson, H., McInnes, L., \& Hamilton, C. (2016). The role of attachment style and anthropomorphism in predicting hoarding behaviours in a non-clinical sample. Personality and Individual Differences, 99, 33-37. doi:10.1016/j.paid.2016. 04.067

Nedelisky, A., \& Steele, M. (2009). Attachment to people and to objects in obsessive-compulsive disorder: An exploratory comparison of hoarders and non-hoarders. Attachment and Human Development, 11(4), 365-383. doi:10.1080/ 14616730903016987

Norberg, M. M., Crone, C., Kakar, V., Kwok, C., \& Grisham, J. R. (under review). Greater interpersonal problems differentiate those who save from those who only excessively acquire possessions. Journal of Obsessive Compulsive and Related Disorders.

Norberg, M. M., Crone, C., Kwok, C., \& Grisham, J. R. (2018). Anxious attachment and excessive acquisition: The mediating roles of anthropomorphism and distress intolerance. Journal of Behavioral Addictions, 7(1), 171-180. doi:10.1556/2006.7. 2018.08
Norberg, M. M., Keyan, D., \& Grisham, J. R. (2015). Mood influences the relationship between distress intolerance and discarding. Journal of Obsessive-Compulsive and Related Disorders, 6, 77-82. doi:10.1016/j.jocrd.2015.06.005

Olivier, J., May, W. L., \& Bell, M. L. (2017). Relative effect sizes for measures of risk. Communications in Statistics - Theory and Methods, 46(14), 6774-6781. doi:10.1080/03610926. 2015.1134575

Postlethwaite, A., Kellett, S., \& Mataix-Cols, D. (2019). Prevalence of hoarding disorder: A systematic review and metaanalysis. Journal of Affective Disorders, 256, 309-316. doi:10.1016/j.jad.2019.06.004

Richardson, J. T. E. (2011). Eta squared and partial eta squared as measures of effect size in educational research. Educational Research Review, 6(2), 135-147. doi:10.1016/j.edurev. 2010.12.001

Rindfleish, A., Burroughs, J. E., \& Denton, F. (1997). Family structure, materialism and compulsive buying. Journal of Consumer Research, 23, 312-325. doi:10.1086/209486

Roberts, J. E., Pullig, C., \& David, M. (2019). Family conflict and adolescent compulsive buying behavior. Young Consumers, 20(3), 208-218. doi:10.1108/YC-10-2018-0870

Singh, R., \& Nayak, J. (2016). Effect of family environment on adolescent compulsive buying: Mediating role of selfesteem. Asia Pacific Journal of Marketing and Logistics, 28(3), 396-419. doi:10.1108/APJML-05-2015-0082

Sneath, J., Lacey, R., \& Kennett-Hensel, P. (2009). Coping with a natural disaster: Losses, emotions, and impulsive and compulsive buying. Marketing Letters, 20(1), 45-60. doi:10.1007/ s11002-008-9049-y

Spence, C. (2017). Comfort food: A review. International Journal of Gastronomy and Food Science, 9, 105-109. doi:10.1016/ j.ijgfs.2017.07.001

Steptoe, A., Gibson, E. L., Vuononvirta, R., Williams, E. D., Hamer, M., Rycroft, J. A., Erusalimsky, J. D., \& Wardle, J. (2007). The effects of tea on psychophysiological stress responsivity and post-stress recovery: A randomised doubleblind trial. Psychopharmacology, 190(1), 81-89. doi:10.1007/ s00213-006-0573-2

Timpano, K. R., \& Shaw, A. M. (2013). Conferring humanness: The role of anthropomorphism in hoarding. Personality and Individual Differences, 54(3), 383-388. doi:10.1016/j.paid. 2012.10.007

Tolin, D. F., Frost, R. O., Steketee, G., \& Fitch, K. E. (2008). Family burden of compulsive hoarding: Results of an Internet survey. Behaviour Research and Therapy, 46(3), 334-344. doi:10.1016/j.brat.2007.12.008

Williams, A. D. (2012). Distress tolerance and experiential avoidance in compulsive acquisition behaviours. Australian Journal of Psychology, 64(4), 217-224. doi:10.1111/j.1742-9536. 2012.00055.x

Zaboski, B. A., II, Merritt, O. A., Schrack, A. P., Gayle, C., Gonzalez, M., Guerrero, L. A., Dueñas, J. A., Soreni, N., \& Mathews, C. A. (2019). Hoarding: A meta-analysis of age of onset. Depression and Anxiety, 36(6), 552-564. doi:10.1002/ da. 22896

Zadro, L., Williams, K. D., \& Richardson, R. (2004). How low can you go? Ostracism by a computer is sufficient to lower selfreported levels of belonging, control, self-esteem, and meaningful existence. Journal of Experimental Social Psychology, 40(4), 560-567. doi:10.1016/j.jesp.2003.11.006 